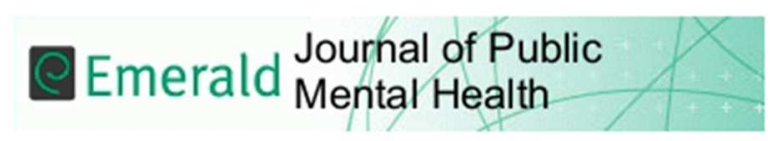

\title{
Relationship between Loneliness and Mental Health in Students.
}

\begin{tabular}{|r|l|}
\hline Journal: & Journal of Public Mental Health \\
\hline Manuscript ID & JPMH-03-2016-0013.R1 \\
\hline Manuscript Type: & Original Research Paper \\
\hline Keywords: & Mental Health, Depression, Anxiety, Eating Disorders, Loneliness \\
\hline \multicolumn{2}{|l}{} \\
\hline
\end{tabular}

\footnotetext{
SCHOLARONE ${ }^{\text {Mx }}$

Manuscripts
} 
Original Research Paper.

\title{
Relationship between Loneliness and Mental Health in Students.
}

\begin{abstract}
Purpose: Previous cross-sectional research has examined effect of loneliness on mental health. This study aimed to examine longitudinal relationships in students.

Design/Methodology: 454 British undergraduate students completed measures of loneliness and mental health at four time points.

Findings: After controlling for demographics and baseline mental health, greater loneliness predicted greater anxiety, stress, depression and general mental health over time. There was no evidence that mental health problems increased loneliness over time. There was no relationship with alcohol problems. Baseline loneliness predicted greater eating disorder risk at follow-up and vice versa.

Research Limitations/Implications: This study is limited by a relatively small and heavily female sample.

Implications: Social and psychological interventions to reduce loneliness in university settings may improve mental health.
\end{abstract}

Key Words: Mental Health; Depression; Anxiety; Eating Disorders; Loneliness. 


\section{Longitudinal Relationships between Loneliness and Mental Health in University Students.}

\section{Introduction}

Loneliness can be defined as "an individual's subjective perception of deficiencies in his or her network of social relationships" (Russell et al, 1984, p.1313). There is therefore a difference between objective social isolation and the feeling of loneliness: it is possible to have limited social contact but not feel lonely and to have regular social contact but feel lonely (Hawkley \& Cacioppo, 2010). This relates to the cognitive discrepancy model of loneliness: in adolescents the difference between desired social activity and actual social activity has been found to predict loneliness (Russell, Cutrona \& McRae, 2012). Studies have shown that levels of frequent loneliness vary between European countries, in the UK such feelings are reported by $6.3 \%$ of those under age $30,5.5 \%$ of those age 30-59 and 7.4\% of those age 60 plus (Yang \& Victor, 2011). Other findings have shown highest rates of loneliness in young and older adults (Victor \& Yang, 2012).

A small body of literature has examined how loneliness is related to mental health problems. Victor and Yang (2012) found that depression was related to loneliness in all age groups. Cacioppo, Hughes, Waite and Hawkley (2006) found a bi-directional relationship over time between loneliness and depression in middle aged and older adults. One recent review suggested that there were links with depression, stress and alcohol problems (Mushtaq et al., 2014). A cross-sectional survey from the United Kingdom (UK) found that whilst loneliness was associated with a broad range of mental health problems, there were particularly strong relationships with depression, phobias and Obsessive Compulsive Disorder (Meltzer et al., 2013).

Starting university may be a high risk time for mental health problems; studies in the United States (US) estimate that nearly half of students meet criteria for a psychiatric disorder (Blanco et al., 2008). Studies in the UK suggest a deterioration in student mental health over time with $9 \%$ of students developing depression and 20\% developing anxiety (Andrews \& Wilding, 2004). A number of factors which exacerbate mental health problems in this population have been examined in particular the impact of financial difficulties (see Richardson, Elliott \& Roberts, 2013 for a review). 
University may also be a time of considerable loneliness due young age, leaving the family home and having to develop new friendships at university. A considerable body of literature has examined correlates and predictors of loneliness in students such as internet addiction (Bozoglan et al.,, 2013; Ceyhan \& Ceyhan, 2008). However, and somewhat surprisingly, there has been little research on the relationship between loneliness and mental health in this population: a study of Malaysian students which found that mental health was more strongly predicted by loneliness than by personality or demographic variables (Md Nordin et al., 2009). A further issue is that the vast majority of research with or without student populations is cross-sectional in nature, thus making it hard to ascertain the specific causal relationships between loneliness and poor mental health. The present investigation therefore aimed to use a longitudinal study to examine the relationship in a student population.

\begin{abstract}
Methods
Design

A prospective survey design was used, following up a non-clinical sample at four time points over 12-14 months. This study used data from an existing study comprising two cohorts over time (Richardson, Elliot \& Roberts, 2015). Data was collected between June 2012 and January 2014 as follows. Time 1 was between February-June 2012 for the first cohort and October-December 2012 for the second cohort. Time 2 was August-September 2012 for the first cohort and February 2013 for the second cohort. Time 3 was November-December 2012 for the first cohort and May-July 2013 for the second cohort. Time 4 was February 2013 for the first cohort and November 2013-January 2014 for the second cohort. This spread over time was due to needing to assess two cohorts from different years at four time points across a year.
\end{abstract}

\title{
Standardised Measures
}

The following standardised measure were used, the Cronbach's alpha $(\alpha)$ is given in the current sample at baseline. 
- $\quad$ Three Item Loneliness Scale (Hughes et al., 2004): Designed as a brief measure of loneliness for large surveys $(\alpha=.84)$. This asks participants to rate how they "feel about different aspects of their life" and how often with questions such as "How often do you feel left out?" This measure was used due to conciseness as a number of questionnaires were administered, but also because it has a high correlation of .82 with the longer 20 item UCLA Loneliness scale (Russell, Penlau \& Cutrona, 1980).

- Seven-Item Generalized Anxiety Disorder Questionnaire (GAD-7) (Spitzer et al., 2006): A measure to detect Generalized Anxiety Disorder, but has also been used as a measure of anxiety in the general population (Löwe et al., 2008) $(\alpha=.91)$.

- Clinical Outcomes Routine Evaluation General Population Version (CORE-GP) (Evans, et al., 2005): A 14 item measure of well-being and general mental health $(\alpha=.90)$.

- Alcohol Use Disorder Identification Test (AUDIT) (Saunders et al., 1993): A 10-item measure of alcohol use abuse and dependence $(\alpha=.87)$.

- Centre for Epidemiological Studies Depression Scale (CES-D) (Radloff, 1977): A 20-item questionnaire designed to measure depression in epidemiological research $(\alpha=.95)$.

- Perceived Stress Scale (PSS) (Cohen et al., 1983): A 10-item measure of perceived stress $(\alpha=.90)$.

- Eating Attitudes Test (EAT) (Garner et al., 1982): A 26-item measure of attitudes towards food and weight suggestive of risk for eating disorder $(\alpha=.93)$.

\section{Participants and Procedure}

Ethical approval was granted by the University of Southampton. Participants were first year British undergraduates recruited from across the UK via students unions. International students were excluded. The research was advertised as a 'Student Mental Health Survey' looking at factors related to mental health in students. Participants were entered into a lottery for vouchers for taking part. Respondents completed a baseline questionnaire online, and were then invited to complete additional online questionnaires at three further time points. For the purposes of this paper, participants who provided data at only one time point were excluded. This left 454 participants. All completed baseline, 
$90.1 \%(\mathrm{n}=409)$ completed time $2,60.4 \%(\mathrm{n}=274)$ time 3 and $53.5 \%(\mathrm{n}=243)$ time 4 . The sample was $77.9 \%(n=352)$ female and $22.1 \%(n=100)$ male. Ethnicity was $89.6 \%(n=405)$ white. Ages ranged from 17 to 57 (mean=19.9 years). This compares to a UK undergraduate average of $56.2 \%$ female, $75.7 \%$ white ethnicity and $44.8 \%$ aged 18 or under (HESA, 2016).

In terms of completing flow-up measures, two chi-square analyses showed that there was also no difference in number of time points completed depending on gender: $\chi^{2}=1.05, p>.05$, or ethnicity: $\chi^{2}=8.20, p>$.05.A Multiple Analysis of Variance showed no difference on baseline loneliness or mental health measures depending on number of time points completed: Wilks' Lambda $F=1.02$ $(14,826), p>.05$.

\section{Statistical Analyses}

Where there were missing values on individual items from standardised measures these were substituted by the mode. Total scores which were therefore continuous scales were used for the analysis. All measures were normally distributed except for the EAT which had abnormal kurtosis. Pearson correlation was used to determine whether loneliness correlated with the measures at time 2, 3, and 4. Where there was a significant correlation, linear hierarchical multiple regression was used to see for each measure at each time point separately, whether baseline loneliness predicted scores on the measure at follow-up after controlling for age, gender and ethnicity. A regression then looked at whether baseline scores on all the measures together predicted loneliness at follow-up after controlling for the same demographics and baseline loneliness.

\section{Results}

\section{Baseline Correlations}

Baseline loneliness correlated with the EAT (Eating Attitudes) at T2 $(r=.41, p<.001)$, T3 $(r=.31, p<.001)$ and T4 $(r=.26, p<.001)$. Also with AUDIT (Alcohol Problems) T2 $(r=.12, p<.01)$, but not at T3 $(r=.05, p>.05)$ or T4 $(r=.-02, p>.05)$. Baseline loneliness correlated with CORE-GP (Global Mental Health) at T2 $(r=.53, p<.001), \mathrm{T} 3(r=.47, p<.001)$ and T4 $(r=.38, p<.001)$ and GAD (General Anxiety) at T2 $(r=.41, p<.001), \mathrm{T} 3(r=.40, p<.001)$ and T4 $(r=.34, p<.001)$. Finally baseline loneliness 
correlated with the CES-D (Depression) at T2 $(r=.51, p<.001)$, T3 $(r=.48, p<.001)$ and T4 $(r=.42$, $p<.001)$ and the PSS (Stress) at T2 $(r=.48, p<.001)$, T3 $(r=.44, p<.001)$ and T4 $(r=.42, p<.001)$.

\section{Linear Regression: Baseline Loneliness and Follow-up Mental Health}

Table 1 displays the results for the final regression models for baseline loneliness predicting follow-up mental health. After demographics and baseline scores were taken into account, baseline loneliness significantly predicted greater EAT scores at T3 $(\beta=.11, p<.05)$ and CES-D at T4 $(\beta=.14$, $p<.05)$. Also PSS at time $2(\beta=.14, p<.01), \mathrm{T} 3(\beta=.14, p<.05)$ and T4 $(\beta=.14, p<.05)$, CORE-GP at T2 $(\beta=.11, p<.05)$ and GAD-7 at T3 $(\beta=.15, p<.01)$.

\section{**Insert Table 1 here**}

\section{Linear Regression: Baseline Mental Health and Follow-up Loneliness}

Linear regression was used to see whether baseline measures predicted follow-up loneliness after controlling for baseline loneliness and demographic variables. The model significantly predicted Loneliness at T2: $F(15,354)=22.77, p<.001, R^{2}=.49$ and at T3: $F(15,231)=12.61, p<.001, R^{2}=.45$, although no mental health measures were significant individual predictors. The model also significantly predicted Loneliness at T4: $F(15,199)=9.64, p<.001, R^{2}=.42$, with higher baseline EAT being a significant individual predictor $(\beta=.22, p<.01)$.

\section{Discussion}

This study aimed to examine longitudinal relationships between loneliness and mental health in university students. There were a number of cross-sectional relationships with greater loneliness linked to greater severity of problems on all the measures employed: eating disorder symptoms, alcohol abuse problems, general mental health, general anxiety, depression and stress. These findings are in line with other cross-sectional studies (Md Nordin et al., 2009; Meltzer et al., 2013). Longitudinally, greater loneliness at baseline predicted increased levels of depression, anxiety, poorer global mental health and heightened risk of an eating disorder. Relationships appeared to be especially 
strong for stress with significant relationships at all time points. These relationships held after demographics and baseline mental health were controlled for, suggesting that loneliness may have exacerbated existing mental health difficulties or led to a direct deterioration of mental health over time. There was no longitudinal relationship with alcohol consumption. Previous studies in this area have shown mixed results with loneliness linked with both more drinking (Sadava \& Thompson, 1986) and less drinking (Kim, 1999).

Thus in terms of determining directions of causality, the results suggest that for general mental health, stress, depression and anxiety, loneliness induces or exacerbates symptoms of poor mental health over time.

As to whether baseline mental health predicted changes in loneliness over time, there was little evidence of this, save for baseline eating attitudes predicting increased loneliness at time four. The relationship appears to be bi-directional. This is consistent with a mutual feedback cycle whereby those who are at risk of an eating disorder are more likely to be lonely, and this loneliness then further exacerbates eating disorder symptoms. These findings back up previous theoretical assertions of a relationship between the two (Levine, 2012).

This study is limited by the predominantly female and white sample; it is unclear why the sample is more heavily female and white than the general UK student population. There is also a relatively small sample, however the sample size is sufficient for multiple regression if a formula of minimum sample size of $n \geq 104+$ number of predictors is used. It is to be noted that owing to the number of regressions completed an increased risk of a type I error is present. It is also important to note that the EAT was not normally distributed and as such does not meet some of the assumptions on which regression analysis is predicated, although regression analysis is often robust with respect to such violation (Fox, 1984). There were high levels of drop-out and the reason for such drop-out is not known though loneliness, mental health and demographic variables did not have an impact. A longer follow-up would have been useful but was not plausible due to this level of drop out.

As the demographics of student populations change with the globalisation and expansion of higher education it may be important to look at different sub-groups within this. A number of such groups within the student population may be at greater risk of loneliness - international students may 
also have been interesting to include as nearly two thirds in one study reported feeling lonely (Sawir et al., 2008) while social class background may also be rlated to the ease with which students make the transition from home to the university. More research is called for in both these areas.

The current study has employed a pragmatic quickly completed measure of loneliness and does not enter into a debate as to whether loneliness itself is best conceptualised as a state or trait (see Perlman and Peplau, (1982), de Jong Gierveld, (1998) and Bekhet, Zausziewski and Nakhla (2008) for wider discussion of the concept). However given the observed empirical associations between the baseline measure of loneliness employed here and the mental health of the respondents at subsequent time points we would argue that this is a moot point for the validity of the findings. It may of course be of some relevance when considering suitable intervention or prevention.

Our conclusion is that this study provides evidence that loneliness exacerbates mental health problems in students. Further research is of course needed to confirm these findings and identify the specific psychological mechanisms involved. These findings have important implications for the provision of mental health services on campus and specifically for those newly arrived. A previous meta-analysis (Masi et al.,2011) identified a number of interventions for loneliness such as enhancing social support, social skills training and increasing opportunities for social contact, but found that targeting maladaptive social cognitions were the most effective. Thought needs to be given to how such interventions, adapted for a university setting, may serve to also benefit students' mental health. Efforts to address student mental health within an institution may well proceed more efficiently by the provision of social support within students' own departments, for example through mentoring schemes provided by other students and from staff or tutor input. Different initiatives within different departments may also warranted and student's unions may have a valuable role in encouraging students into activities such as society which might help mitigate feelings of loneliness. Perhaps simply discussing the effect of loneliness on mental health in universities may in itself help students feel less isolated.

\section{Acknowledgements}


1

2

3

4

5

6

7

8

9

10

11

12

13

14

15

16

17

18

19

20

21

22

23

24

25

26

27

28

29

30

31

32

33

34

35

36

37

38

39

40

41

42

43

44

45

46

47

48

49

50

51

52

53

54

55

56

57

58

59

60
Thank you to the universities who helped with recruitment and those who took part in the survey. Thank you to Harriet Collie who helped perform a literature search to help inform this paper and Megan Jansen who assisted in the write-up. This data was collected as part of a Doctorate in Clinical Psychology, which is funded by the UK National Health Service. 


\section{References}

Andrews, B., \& Wilding, J. M. (2004). The relation of depression and anxiety to life-stress and achievement in students. British Journal of Psychology, 95(4), 509-521.

Bekhet, A.K., Zausziewski, J.A.and Nakhla, W.E. (2008) Loneliness: a conceptual analysis. Nursing Forum, 43(4), 207-13.

Blanco, C., Okuda, M., Wright, C., Hasin, D. S., Grant, B. F., Liu, S.-M., et al. (2008). Mental health of college students and their non-college-attending peers: results from the National Epidemiologic Study on Alcohol and Related Conditions. Archives of General Psychiatry, 65(12), 1429.

Bozoglan, B., Demirer, V. and Sahin, I. (2013), "Loneliness, self-esteem, and life satisfaction as predictors of Internet addiction: A cross-sectional study among Turkish university students", Scandinavian Journal of Psychology, Vol. 54 No. 4, pp. 313-319.

Cacioppo, J. T., Hughes, M. E., Waite, L. J., Hawkley, L. C., \& Thisted, R. A. (2006). Loneliness as a specific risk factor for depressive symptoms: cross-sectional and longitudinal analyses. Psychology and aging, 21(1), 140.

Ceyhan, A.A., and Ceyhan, E. (2008), "Loneliness, depression, and computer self-efficacy as predictors of problematic internet use", CyberPsychology \& Behavior, Vol. 11 No. 6, pp. 699701.

Cohen, S., Kamarck, T. and Mermelstein, R. (1983), “A global measure of perceived stress”, Journal of health and social behavior, Vol. 24 No. 4, pp. 385-396.

de Jong Gierveld, J. (1998) A review of loneliness: concept and definitions, determinants and consequences. Reviews in Clinical Gerontology, 8(1), 73-80.

Evans, C., Connell, J., Audin, K., Sinclair, A. and Barkham, M. (2005), "Rationale and development of a general population well-being measure: Psychometric status of the GP-CORE in a student sample”, British Journal of Guidance \& Counselling, Vol. 22, No. 2, pp. 153-173.

Fox, J. (1984) Linear statistical models and related models. New York. John Wiley. 
Garner, D.M., Olmsted, M.P., Bohr, Y. and Garfinkel, P.E. (1982), The eating attitudes test: psychometric features and clinical correlates. Psychological medicine, Vol. 12 No. 4, pp. 871878.

Hawkley, L. C., \& Cacioppo, J. T. (2010). Loneliness matters: a theoretical and empirical review of consequences and mechanisms. Annals of Behavioral Medicine, 40(2), 218-227.

Higher Education Statistics Agency (2016). Data and Analysis: Students and Graduates. Available at https://www.hesa.ac.uk/data-and-analysis/students (accessed 14th October 2016).Hughes, M.E., Waite, L.J., Hawkley, L.C. and Cacioppo, J.T. (2004), “A Short Scale for Measuring Loneliness in Large Surveys: Results From Two Population-Based Studies", Research on aging, Vol. 26, No. 6, pp. 655-672.

Kim, O.S. (1999). The effects of loneliness on alcohol drinking, smoking, and health perception in college students. Journal of Korean Academy of Nursing, Vol. 29 No. 1, pp. 107-116.

Levine, M.P. (2012). Loneliness and eating disorders. The Journal of Psychology, Vol. 146 No1-2, pp. 243-257.

Löwe, B., Decker, O., Müller, S., Brähler, E., Schellberg, D., Herzog, W. and Herzberg, P.Y. (2008), "Validation and standardization of the Generalized Anxiety Disorder Screener (GAD-7) in the general population", Medical Care, Vol. 46 No. 3, pp. 266-274.

Masi, C.M., Chen, H.-Y., Hawkley, L.C. and Cacioppo, J.T. (2011), “A meta-analysis of interventions to reduce loneliness", Personality and Social Psychology Review, Vol. 15 No. 3, pp. 219-266.

Md Nordin, N., Abu Talib, M. and Yaacob, S.N. (2009), "Personality, loneliness and mental health among undergraduates at Malaysian Universities”, European Journal of Scientific Research, Vol. 26 No. 2, pp. 285-298.

Meltzer, H., Bebbington, P., Dennis, M.S., Jenkins, R., McManus, S. and Brugha, T.S. (2013), "Feelings of loneliness among adults with mental disorder", Social Psychiatry and Psychiatric Epidemiology, Vol. 28 No. 1, pp. 5-13.

Mushtaq, R., Shoib, S., Shah, T., \& Mushtaq, S. (2014), "Relationship between loneliness, psychiatric disorders and physical health? A review on the psychological aspects of loneliness", Journal of Clinical and Diagnostic Research, Vol 8 No. 9, WE01-WE04. 
Peplau, L. A. and Perlman, D. (1982) Loneliness. A sourcebook of current research and therapy. New York. John Wiley and Sons.

Radloff, L.S. (1977), "The CES-D scale a self-report depression scale for research in the general population”, Applied Psychological Measurement, Vol. 1 No. 3, pp. 385-401.

Richardson, T., Elliot, P \& Roberts, R. (2015) The Impact of Tuition Fees Amount on Mental Health over Time in British Students. Journal of Public Health, 37(3), 412-418.

Richardson, T., Elliott, P., \& Roberts, R. (2013). The relationship between personal unsecured debt and mental and physical health: a systematic review and meta-analysis. Clinical Psychology Review, 33(8), 1148-1162.

Russell, D. W., Cutrona, C. E., McRae, C., \& Gomez, M. (2012). Is loneliness the same as being alone? The Journal of psychology, 146(1-2), 7-22.

Russell, D., Cutrona, C.E., Rose, J. and Yurko, K. (1984). Social and emotional loneliness: an examination of Weiss's typology of loneliness. Journal of Personality and Social Psychology, Vol. 46 No. 6, pp. 1313-1321.

Russell, D., Peplau, L.A. and Cutrona, C.E. (1980). The Revised UCLA Loneliness Scale: Concurrent and Discriminant Validity Evidence. Journal of Personality and Social Psychology 39, 47280.Sadava, S. and Thompson, M. (1986)., "Loneliness, social drinking, and vulnerability to alcohol problems". Canadian Journal of Behavioural Science, Vol. 18 No. 2pp. 133-139.

Saunders, J.B., Aasland, O.G., Babor, T.F., De la Fuente, J.R. and Grant, M. (1993), “Development of the alcohol use disorders identification test (AUDIT). WHO collaborative project on early detection of persons with harmful alcohol consumption-II." Addiction Vol. 88, No. 6 pp. 791804.

Sawir, E., Marginson, S., Deumert, A., Nyland, C. and Ramia, G. (2008), "Loneliness and international students: An Australian study.” Journal of Studies in International Education, Vol. 12 No. 2, pp. 148-180.

Spitzer, R.L., Kroenke, K., Williams, J.B. and Löwe, B. (2006), "A brief measure for assessing generalized anxiety disorder: the GAD-7.” Archives of Internal Medicine, Vol. 166, No. 10, 1092-1097. 
1

2

3

4

5

6

7

8

9

10

11

12

13

14

15

16

17

18

19

20

21

22

23

24

25

26

27

28

29

30

31

32

33

34

35

36

37

38

39

40

41

42

43

44

45

46

47

48

49

50

51

52

53

54

55

56

57

58

59

60
Victor, C. R., \& Yang, K. (2012). The prevalence of loneliness among adults: a case study of the United Kingdom. The Journal of psychology, 146(1-2), 85-104.

Yang, K., \& Victor, C. (2011). Age and loneliness in 25 European nations. Ageing and Society, 31(08), 1368-1388. 
Table 1: Final regression models of baseline loneliness predicting follow-up mental health

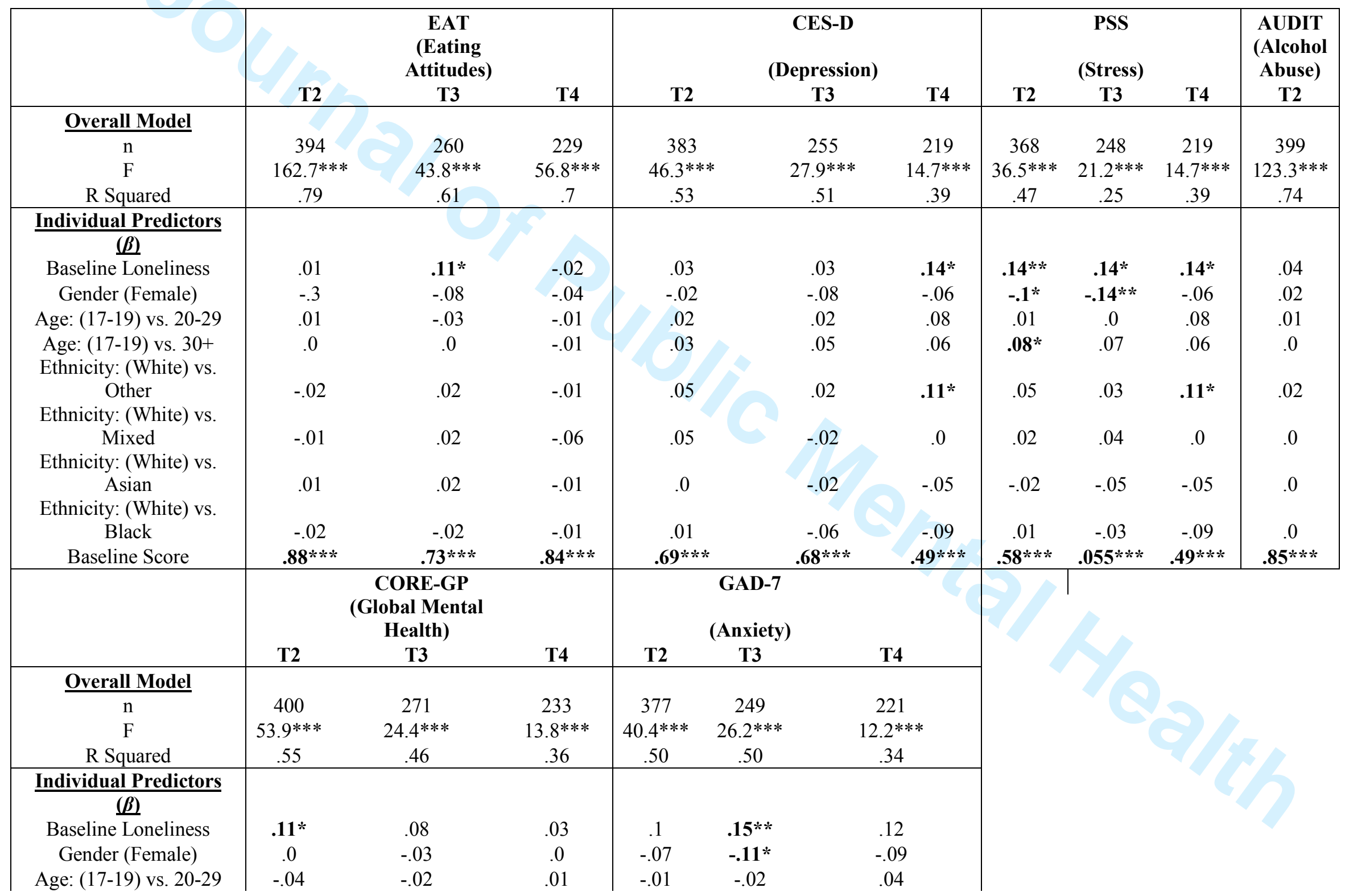




\section{Page 15 of 28}

Journal of Public Mental Health

1
2
3
4
5
6
7
8
9
10
11
12
13
14
15
16
17
18
19
20
21
22
23
24
25
26
27
28
29
30
31
32
33
34
35
36
37
38
39
40
41
42
43
44
45

\begin{tabular}{|l|ccc|ccc|} 
Age: (17-19) vs. 30+ & .01 & .0 & .03 & .07 & .02 & .02 \\
$\begin{array}{c}\text { Ethnicity: (White) vs. } \\
\text { Other }\end{array}$ & $\mathbf{. 0 7 *}$ & .04 & .03 & .06 & .02 & .06 \\
$\begin{array}{c}\text { Ethnicity: (White) vs. } \\
\text { Mixed }\end{array}$ & .01 & -.05 & -.03 & .02 & -.03 & -.06 \\
$\begin{array}{c}\text { Ethnicity: (White) vs. } \\
\text { Asian }\end{array}$ & -.03 & -.05 & -.03 & -.01 & -.04 & -.03 \\
$\begin{array}{c}\text { Ethnicity: (White) vs. } \\
\text { Black }\end{array}$ & .03 & -.04 & -.09 & .01 & -0.04 & -.07 \\
Baseline Score & $\mathbf{. 6 7 * * *}$ & $\mathbf{. 6 2 * * *}$ & $\mathbf{. 5 6 * * *}$ & $\mathbf{. 6 3 * *}$ & $\mathbf{. 5 9 * * *}$ & $\mathbf{. 4 8 * * *}$ \\
\hline$*=p<.05, * * p<.01, * * * p<.001$ & & &
\end{tabular}

Please note dummy/reference variables are shown in brackets. 


\title{
Brief Report.Original Research Paper.
}

\section{Relationship between Loneliness and Mental Health in Students.}

\begin{abstract}
Purpose: Previous cross-sectional research has examined effect of loneliness on mental health. This study aimed to examine longitudinal relationships in students.

Design/Methodology: 454 British undergraduate students completed measures of loneliness and mental health at four time points.

Findings: After controlling for demographics and baseline mental health, greater loneliness predicted greater anxiety, stress, depression and general mental health over time. There was no evidence that mental health problems increased loneliness over time. There was no relationship with alcohol problems. Baseline loneliness predicted greater eating disorder risk at follow-up and vice versa.

Research Limitations/Implications: This study is limited by a relatively small and heavily female sample.

Implications: Social and psychological interventions to reduce loneliness in university settings may improve mental health.
\end{abstract}

Key Words: Mental Health; Depression; Anxiety; Eating Disorders; Loneliness. 


\section{Longitudinal Relationships between Loneliness and Mental Health in University Students.}

\section{Introduction}

A large body of literature has demonstrated a relationship between social support and mental health in a range of different populations. For example poor social support has been linked to increased risk of depression in pregnant women (Pajulo et al., 2001), more symptoms of depression and anxiety following stillbirth (Cacciatore et al, 2009), and greater anxiety in those undergoing treatment for ovarian cancer (Hipkins et al, 2004). A meta analysis has also found that perceived social support was relatedis linked to mental health in emergency services personnel (Prati \& Pietrantoni, 2010).

One factor which may account for this relationship is loneliness, whichLoneliness can be defined as "an individual's subjective perception of deficiencies in his or her network of social relationships"," (Russell et al, 1984, p.1313). There is therefore a difference between objective social isolation and the feeling of loneliness: it is possible to have limited social contact but not feel lonely and to have regular social contact but feel lonely (Hawkley \& Cacioppo, 2010). This relates to the cognitive discrepancy model of loneliness: in adolescents the difference between desired social activity and actual social activity has been found to predict loneliness (Russell, Cutrona \& McRae, 2012). Studies have shown that levels of frequent loneliness vary between European countries, in the UK such feelings are reported by $6.3 \%$ of those under age $30,5.5 \%$ of those age $30-59$ and $7.4 \%$ of those age 60 plus (Yang \& Victor, 2011). Other findings have shown highest rates of loneliness in young and older adults (Victor \& Yang, 2012).

A small body of literature has examined how loneliness is specifically is-related to mental health problems. Victor and Yang (2012) found that depression was related to loneliness in all age groups. Cacioppo, Hughes, Waite and Hawkley (2006) found a bi-directional relationship over time between loneliness and depression in middle aged and older adults. One recent review eencludessuggested that it may be linkedthere were links with depression, stress and alcohol problems (Mushtaq et al., 2014). A cross-sectional survey from the United Kingdom (UK) found that whilst loneliness was linked to everyassociated with a broad range of mental health problem, but toproblems, 
there were particularly strong relationships with depression, phobias and Obsessive Compulsive Disorder in particular(Meltzer et al., 2013).

Starting university may be a high risk time for mental health problems; studies in the United $\underline{\text { States (US) estimate that nearly half of students meet criteria for a psychiatric disorder (Blanco et al., }}$ 2008). Studies in the UK suggest a deterioration in student mental health over time with $9 \%$ of students developing depression and 20\% developing anxiety (Andrews \& Wilding, 2004). A number of factors which exacerbate mental health problems in this population have been examined in particular the impact of financial difficulties (see Richardson, Elliott \& Roberts, 2013 for a review).

University may also be a time of considerable loneliness due young age, to-leaving the family home and having to develop new friendships at university. A considerable body of literature has examined correlates and predictors of loneliness in students such as internet addiction (Bozoglan et al.,, 2013; Ceyhan \& Ceyhan, 2008)-in students. However, and somewhat surprisingly, there ishas been little research on the relationship between loneliness and mental health in this population: a study of Malaysian students which found that mental health was more strongly predicted by loneliness than by personality or demographic variables (Md Nordin et al., 2009). In addition, $\underline{A}$ further issue is that the vast majority of research with or without student populations is cross-sectional in nature, therebythus making it hard to determine whetherascertain the specific causal relationships between loneliness leads toand poor mental health-or vice versa. The present investigation therefore aimed to use a longitudinal study to examine the relationship in a student population.

\section{Methods}

Design

A prospective survey design was used, following up a non-clinical sample at four time points over approximately one year.1812-14 months. This study used data from an existing study= comprising-several two cohorts- over time (Richardson, Elliot \& Roberts, 2015). Data was collected between June 2012 and January 2014 as follows. Time 1 was between February-June 2012 for the 2014first cohort and October-December 2012 for the 2012second cohort. Time 2 was AugustSeptember 2012 for the 2014first cohort and February 2013 for the 2012 second cohort. Time 3 was 
November-December 2012 for the 2014first cohort and May-July 2013 for the 2012second cohort. Time 4 was February 2013 for the 2014first cohort and November 2013-January 2014 for the 2012second cohort. This spread over time was due to needing to assess two cohorts from different years at four time points across a year.

\section{Standardised Measures}

The following standardised measure were used, the Cronbach's alpha $(\alpha)$ is given in the current sample at baseline.

- Three Item Loneliness Scale (Hughes et al., 2004): Designed as a brief measure of loneliness for large surveys $(\alpha=84)$. This asks participants to rate how they "feel about different aspects of their life" and how often with questions such as "How often do you feel left out?" This measure was used due to conciseness as a number of questionnaires were administered, but also because it has a high correlation of .82 with the longer 20 item UCLA Loneliness scale (Russell, Penlau \& Cutrona, 1980).

- Seven-Item Generalized Anxiety Disorder Questionnaire (GAD-7) (Spitzer et al., 2006): A measure to detect Generalized Anxiety Disorder, but has also been used as a measure of anxiety in the general population (Löwe et al., 2008) $(\alpha=.91)$.

- Clinical Outcomes Routine- Evaluation General Population Version (CORE-GP) (Evans, et al., 2005): A 14 item measure of well-being and general mental health $(\alpha=.90)$.

- Alcohol Use Disorder Identification Test (AUDIT) (Saunders et al., 1993): A 10-item measure of alcohol use abuse and dependence $-(\alpha=.87)$.

- Centre for Epidemiological Studies Depression Scale (CES-D) (Radloff, 1977): A 20-item questionnaire designed to measure depression in epidemiological research $-(\alpha=.95)$.

- Perceived Stress Scale (PSS) (Cohen et al., 1983): A 10-item measure of perceived stress $(\alpha=.90)$.

- Eating Attitudes Test (EAT) (Garner et al., 1982): A 26-item measure of attitudes towards food and weight suggestive of risk for eating disorder $(\alpha=.93)$. 


\section{Participants and Procedure}

Ethical approval was granted by the University of Southampton. Participants were first year British undergraduates recruited from across the UK via students unions. International students were excluded. The research was advertised as a 'Student Mental Health Survey' looking at factors related to mental health in students. Participants were entered into a lottery for vouchers for taking part. StudentsRespondents completed a baseline questionnaire online, and were then invited to ake part at ancomplete additional online questionnaires at three further time points. For the purposes of this paper, participants who eompletedprovided data at only one time point were excluded. This left 454 participants. All completed baseline, 90.1\% $(n=409)$ completed time 2, 60.4\% $(n=274)$ time 3 and $53.5 \%(n=243)$ time 4 . The sample was $77.9 \%(n=352)$ female and $22.1 \%(n=100)$ male. Ethnicity was $89.6 \%(n=405)$ white. Ages ranged from 17 to 57 with a (mean-ef=19.9 years-). This compares to a UK undergraduate average of $56.2 \%$ female, $75.7 \%$ white ethnicity and $44.8 \%$ aged 18 or under (HESA, 2016).

In terms of completing flow-up measures, two chi-square analyses showed that there was also

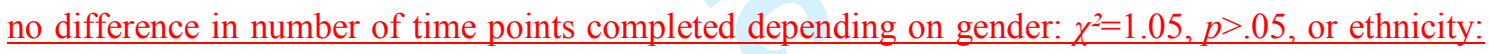
$\chi^{2}=8.20, p>$.05. - A Multiple Analysis of Variance showed no difference on baseline loneliness or mental health measures depending on number of time points completed: Wilks' Lambda $F=1.02$ $(14,826), p>.05$.

\section{Statistical Analyses}

Where there were missing values on individual items from standardised measures these were substituted by the mode. Total scores which were therefore continuous scales were used for the analysis. All measures were normally distributed except for the EAT which had abnormal kurtosis. Pearson correlation was used to determine whether loneliness correlated with the measures at time 2, 3, and 4. Where there was a significant correlation, linear hierarchical multiple regression was used to see for each measure at each time point separately, whether baseline loneliness predicted seorescores on the measure at follow-up after controlling for age, gender, and ethnicity-and baseline loneliness.. 
A regression then looked at whether baseline scores on all the measures together predicted loneliness at follow-up after controlling for the same demographics and baseline loneliness.

\section{Results}

\section{Baseline Correlations}

Baseline loneliness correlated with the EAT (Eating Attitudes) at T2 $(r=.41, p<.001)$, T3 $(r=.31, p<.001)$ and T4 $(r=.26, p<.001)$. Also with AUDIT (Alcohol Problems) T2 $(r=.12, p<.01)$, but not at T3 $(r=.05, p>.05)$ or T4 $(r=.-02, p>.05)$. Baseline loneliness correlated with CORE-GP (Global Mental Health) at T2 $(r=.53, p<.001)$, T3 $(r=.47, p<.001)$ and T4 $(r=.38, p<.001)$ and GAD (General Anxiety $)$ at T2 $(r=.41, p<.001), \mathrm{T} 3(r=.40, p<.001)$ and T4 $(r=.34, p<.001)$. Finally baseline loneliness correlated with the CES-D (Depression) at T2 $(r=.51, p<.001)$, T3 $(r=.48, p<.001)$ and T4 $(r=.42$, $p<.001)$ and the PSS (Stress) at T2 $(r=.48, p<.001), \mathrm{T} 3(r=.44, p<.001)$ and T4 $(r=.42, p<.001)$.

\section{Linear Regression: Baseline Loneliness and Follow-up Mental Health}

Table 1 displays the results for the final regression models for baseline loneliness predicting follow-up mental health. After demographics and baseline scores were taken into account, baseline loneliness significantly predicted greater EAT scores at T3 $(\beta=.11, p<.05)$ and CES-D at T4 $(\beta=.14$, $p<.05)$. Also PSS at time $2(\beta=.14, p<.01), \mathrm{T} 3(\beta=.14, p<.05)$ and T4 $(\beta=.14, p<.05)$, CORE-GP at T2 $(\beta=.11, p<.05)$ and GAD-7 at T3 $(\beta=.15, p<.01)$.

\section{**Insert Table 1 here**}

\section{Linear Regression: Baseline Mental Health and Follow-up Loneliness}

Linear regression was used to see whether baseline measures predicted follow-up loneliness after controlling for baseline loneliness and demographic variables. The-final model significantly predicted Loneliness at T2: $F(15,354)=22.77, p<.001, R^{2}=.49$, and at 3 : $F(15,231)=12.61$, $p<.001, R^{2}=.45$, although no mental health measures were significant individual predictors. -The-finat model significantly predicted Loneliness at T3: $F(15,231)=12.61, p<.001, R^{2}=.45$, however no mental 
health measures were significant individual predictors. Finally, the final modelalso significantly predicted Loneliness at T4: $F(15,199)=9.64, p<.001, R^{2}=.42$, with higher baseline EAT being a significant individual predictor $(\beta=.22, p<.01)$.

\section{Discussion}

This study aimed to examine longitudinal relationships between loneliness and mental health in university students. There were a number of cross-sectional relationships with greater loneliness linked to more severe symptomsgreater severity of problems on all variables measuredthe measures employed: eating disorder symptoms, alcohol abuse problems, general mental health, general anxiety, depression and stress. These findings are in line with other cross-sectional studies (Md Nordin et al., 2009; Meltzer et al., 2013). Longitudinally, greater loneliness at baseline predicted more severe symptemsincreased levels of depression, anxiety, poorer global mental health and heightened risk of an eating disorder-risk. Relationships appeared to be especially strong for stress with significant relationships at all time points. These relationships held after demographics and baseline mental health were controlled for, suggesting that loneliness may have exacerbated existing mental health difficulties or led to a direct deterioration of mental health over time. There was no relationshipslongitudinal relationship with alcohol consumption: previous. Previous studies in this area have shown mixed results with loneliness linked with both more drinking (Sadava \& Thompson, 1986) and less drinking (Kim, 1999).

Looking at whether baseline mental health predicted changes in loneliness in mental health over time, there was only one significant variable which was for greater baseline eating attitudes increasing loneliness at time four after controlling for demographies and baseline loneliness. Thus in terms of determining directions of causality, the results suggest that for general mental health, stress, depression and anxiety, loneliness induces or exacerbates symptoms of poor mental health over time.

There is no evidence that these mental health problems increase loneliness over time in this population.

The exception is-As to whether baseline mental health predicted changes in loneliness over

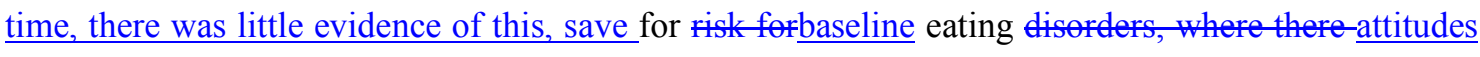


predicting increased loneliness at time four. The relationship appears to be a-bi-directional relationship-. This is consistent with toneliness. It may be that there is a viciousa mutual feedback cycle whereby those who are at risk of an eating disorder are more likely to be lonely, and this loneliness then further exacerbates eating disorder symptoms. These findings back up previous theoretical assertions of a relationship between the two (Levine, 2012).

This study is limited by the predominantly female and white sample; it is unclear why the sample is more heavily female and white than the general UK student population. There is also a and relatively small sample, however the sample size is sufficient for multiple regression if a formula of minimum sample size of $n \geq 104+$ number of predictors is used. International students may also have been interesting It is to include as nearly two thirds in one study reported feeling lonely (Sawir et al., 2008). Duebe noted that owing to the number of regressions completed there is-an increased risk of a type I error, and it is present. It is also important to note that the EAT was not normally distributed and as such does not meet some of the assumptions on which regression analysis is predicated, although regression analysis is often robust with respect to such violation (Fox, 1984). There were high levels of drop-out and the reason for such drop-out is not known though loneliness, mental health and demographic variables did not have an impact. A longer follow-up would have been useful but was not plausible due to this level of drop out.

As the demographics of student populations change with the globalisation and expansion of higher education it may be important to look at different sub-groups within this. A number of such groups within the student population may be at greater risk of loneliness - international students may also have been interesting to include as nearly two thirds in one study reported feeling lonely (Sawir et al., 2008) while social class background may also be rlated to the ease with which students make the transition from home to the university. More research is called for in both these areas.

InThe current study has employed a pragmatic quickly completed measure of loneliness and does not enter into a debate as to whether loneliness itself is best conceptualised as a state or trait (see Perlman and Peplau, (1982), de Jong Gierveld, (1998) and Bekhet, Zausziewski and Nakhla (2008) for wider discussion of the concept). However given the observed empirical associations between the baseline measure of loneliness employed here and the mental health of the respondents at subsequent 
time points we would argue that this is a moot point for the validity of the findings. It may of course be of some relevance when considering suitable intervention or prevention.

Our conclusion, is that this study suggestsprovides evidence that loneliness exacerbates mental health problems in students. Further research is of course needed to confirm these findings and identify the specific psychological mechanisms involved. These findings have important implications for the provision of mental health services on campus and specifically for those newly arrived. A previous meta-analysis (Masi et al.,2011) identified a number of interventions for loneliness such as enhancing social support, social skills training and increasing opportunities for social contact, but found that targeting maladaptive social cognitions were the most effective. Thought needs to be given to how such interventions, adapted for a university setting, may serve to also benefit student's mental health.students' mental health. Efforts to address student mental health within an institution may well proceed more efficiently by the provision of social support within students' own departments, for example through mentoring schemes provided by other students and from staff or tutor input. Different initiatives within different departments may also warranted and student's unions may have a valuable role in encouraging students into activities such as society which might help mitigate feelings of loneliness. Perhaps simply discussing the effect of loneliness on mental health in universities may in itself help students feel less isolated.

\section{Acknowledgements}

Thank you to the universities who helped with recruitment and those who took part in the survey. Thank you to Harriet Collie who helped perform a literature search to help inform this paper and Megan Jansen who assisted in the write-up. This data was collected as part of a Doctorate in Clinical Psychology, which is funded by the UK National Health Service. 


\section{References}

Andrews, B., \& Wilding, J. M. (2004). The relation of depression and anxiety to life-stress and achievement in students. British Journal of Psychology, 95(4), 509-521.

Bekhet, A.K., Zausziewski, J.A.and Nakhla, W.E. (2008) Loneliness: a conceptual analysis. Nursing Forum, 43(4), 207-13.

Blanco, C., Okuda, M., Wright, C., Hasin, D. S., Grant, B. F., Liu, S.-M., et al. (2008). Mental health of college students and their non-college-attending peers: results from the National Epidemiologic Study on Alcohol and Related Conditions. Archives of General Psychiatry, $\underline{65(12), 1429 .}$

Bozoglan, B., Demirer, V. and Sahin, I. (2013), "Loneliness, self-esteem, and life satisfaction as predictors of Internet addiction: A cross-sectional study among Turkish university students", Scandinavian Journal of Psychology, Vol. 54 No. 4, pp. 313-319.

Cacciatere, J., Schnebly, S. and Froen, J. F. (2009), "The effects of social support on maternal anxiety and depression after stillbirth", Health of Social Care in the Commanity, Vol. 17 No. 2, pp. 167176.

Cacioppo, J. T., Hughes, M. E., Waite, L. J., Hawkley, L. C., \& Thisted, R. A. (2006). Loneliness as a specific risk factor for depressive symptoms: cross-sectional and longitudinal analyses. Psychology and aging, 21(1), 140.

Ceyhan, A.A., and Ceyhan, E. (2008), "Loneliness, depression, and computer self-efficacy as predictors of problematic internet use", CyberPsychology \& Behavior, Vol. 11 No. 6, pp. 699701.

Cohen, S., Kamarck, T. and Mermelstein, R. (1983), “A global measure of perceived stress”, Journal of health and social behavior, Vol. 24 No. 4, pp. 385-396.

de Jong Gierveld, J. (1998) A review of loneliness: concept and definitions, determinants and consequences. Reviews in Clinical Gerontology, 8(1), 73-80. 
Evans, C., Connell, J., Audin, K., Sinclair, A. and Barkham, M. (2005), "Rationale and development of a general population well-being measure: Psychometric status of the GP-CORE in a student sample”, British Journal of Guidance \& Counselling, Vol. 22, No. 2, pp. 153-173.

Fox, J. (1984) Linear statistical models and related models. New York. John Wiley.

Garner, D.M., Olmsted, M.P., Bohr, Y. and Garfinkel, P.E. (1982), The eating attitudes test: psychometric features and clinical correlates. Psychological medicine, Vol. 12 No. 4, pp. 871878.

Hawkley, L. C., \& Cacioppo, J. T. (2010). Loneliness matters: a theoretical and empirical review of consequences and mechanisms. Annals of Behavioral Medicine, 40(2), 218-227.

Higher Education Statistics Agency (2016). Data and Analysis: Students and Graduates. Available at https://www.hesa.ac.uk/data-and-analysis/students (accessed 14th October 2016).

Hipkins, J., Whitworth, M., Tarrier, N. and Jayson, G. (2004), "Social support, anxiety and depression after chemotherapy for ovarian cancer: A prospective study", British Journal of Health Psychology, Vol.9 No.4, pp. $569-581$.

Hughes, M.E., Waite, L.J., Hawkley, L.C. and Cacioppo, J.T. (2004), “A Short Scale for Measuring Loneliness in Large Surveys: Results From Two Population-Based Studies”, Research on aging, Vol. 26, No. 6, pp. 655-672.

Kim, O.S. (1999). The effects of loneliness on alcohol drinking, smoking, and health perception in college students. Journal of Korean Academy of Nursing, Vol. 29 No. 1, pp. 107-116.

Levine, M.P. (2012). Loneliness and eating disorders. The Journal of Psychology, Vol. 146 No1-2, pp. 243-257.

Löwe, B., Decker, O., Müller, S., Brähler, E., Schellberg, D., Herzog, W. and Herzberg, P.Y. (2008), "Validation and standardization of the Generalized Anxiety Disorder Screener (GAD-7) in the general population", Medical Care, Vol. 46 No. 3, pp. 266-274.

Masi, C.M., Chen, H.-Y., Hawkley, L.C. and Cacioppo, J.T. (2011), “A meta-analysis of interventions to reduce loneliness", Personality and Social Psychology Review, Vol. 15 No. 3, pp. 219-266. 
Md Nordin, N., Abu Talib, M. and Yaacob, S.N. (2009), "Personality, loneliness and mental health among undergraduates at Malaysian Universities”, European Journal of Scientific Research, Vol. 26 No. 2, pp. 285-298.

Meltzer, H., Bebbington, P., Dennis, M.S., Jenkins, R., McManus, S. and Brugha, T.S. (2013), "Feelings of loneliness among adults with mental disorder", Social Psychiatry and Psychiatric Epidemiology, Vol. 28 No. 1, pp. 5-13.

Mushtaq, R., Shoib, S., Shah, T., \& Mushtaq, S. (2014), "Relationship between loneliness, psychiatric disorders and physical health? A review on the psychological aspects of loneliness", Journal of Clinical and Diagnostic Research, Vol 8 No. 9, WE01-WE04.

Pajulo, M., Savonlahti, E., Sourander, A., Helenius, H. and Piha, J. (2001), "Antenatal depression, substance dependency and social support", Journal of Affective Disorders, Vol. 65 No. 1, pp. 917.

Peplau, L. A. and Perlman, D. (1982) Loneliness. A sourcebook of current research and therapy. New York. John Wiley and Sons.

Prati, G. and Pietrantoni, L. (2010), "The relation of perceived and received social support to mental health among first responders: a meta-analytic review", Journal of Community Psychology, Vol. 38 No. 3, pp. $403-417$.

Radloff, L.S. (1977), “The CES-D scale a self-report depression scale for research in the general population”, Applied Psychological Measurement, Vol. 1 No. 3, pp. 385-401.

Richardson, T., Elliot, P \& Roberts, R. (2015) The Impact of Tuition Fees Amount on Mental Health over Time in British Students. Journal of Public Health, 37(3), 412-418.

Richardson, T., Elliott, P., \& Roberts, R. (2013). The relationship between personal unsecured debt and mental and physical health: a systematic review and meta-analysis. Clinical Psychology Review, 33(8), 1148-1162.

Russell, D. W., Cutrona, C. E., McRae, C., \& Gomez, M. (2012). Is loneliness the same as being alone? The Journal of psychology, 146(1-2), 7-22. 
Russell, D., Cutrona, C.E., Rose, J. and Yurko, K. (1984). Social and emotional loneliness: an examination of Weiss's typology of loneliness. Journal of Personality and Social Psychology, Vol. 46 No. 6, pp. 1313-1321.

Russell, D., Peplau, L.A. and Cutrona, C.E. (1980). The Revised UCLA Loneliness Scale: Concurrent and Discriminant Validity Evidence. Journal of Personality and Social Psychology 39, 472$\underline{80 .}$

Sadava, S. and Thompson, M. (1986)., "Loneliness, social drinking, and vulnerability to alcohol problems". Canadian Journal of Behavioural Science, Vol. 18 No. 2pp. 133-139.

Saunders, J.B., Aasland, O.G., Babor, T.F., De la Fuente, J.R. and Grant, M. (1993), "Development of the alcohol use disorders identification test (AUDIT). WHO collaborative project on early detection of persons with harmful alcohol consumption-II.” Addiction Vol. 88, No. 6 pp. 791804.

Sawir, E., Marginson, S., Deumert, A., Nyland, C. and Ramia, G. (2008), "Loneliness and international students: An Australian study." Journal of Studies in International Education, Vol. 12 No. 2, pp. 148-180.

Spitzer, R.L., Kroenke, K., Williams, J.B. and Löwe, B. (2006), “A brief measure for assessing generalized anxiety disorder: the GAD-7.” Archives of Internal Medicine, Vol. 166, No. 10, 1092-1097.

Victor, C. R., \& Yang, K. (2012). The prevalence of loneliness among adults: a case study of the United Kingdom. The Journal of psychology, 146(1-2), 85-104.

Yang, K., \& Victor, C. (2011). Age and loneliness in 25 European nations. Ageing and Society, $\underline{31(08), 1368-1388 .}$ 